This document is published in:

Actas Dermo-Sifiliográficas, Vol. 104, no 10 (2013), pp. 877-882

DOI: http://dx.doi.org/10.1016/j.ad.2012.11.018

(C) 2012 Elsevier España S.L. and AEDV. 


\title{
First Symposium of Ichthyosis Experts
}

\section{A. Hernández-Martín, ${ }^{\mathrm{a}, *}$ A. Torrelo-Fernández, ${ }^{\mathrm{a}}$ R. de Lucas-Laguna, ${ }^{\mathrm{b}} \mathrm{F}$. Casco, ${ }^{\mathrm{c}}$ R. González-Sarmiento, ${ }^{d}$ A. Vega, ${ }^{e}$ J.L. Pedreira-Massa, ${ }^{f}$ P. de Unamuno-Pérez, ${ }^{\mathrm{g}}$ F. Larcher, ${ }^{\text {h I. Arroyo, }{ }^{i} \text { H. Traupe }}$}

\author{
a Servicio de Dermatología, Hospital Infantil Niño Jesús, Madrid, Spain \\ b Servicio de Dermatología, Hospital La Paz, Madrid, Spain \\ c Servicio de Anatomía Patológica, Hospital Infantil Niño Jesús, Madrid, Spain \\ d Unidad de Medicina Molecular, Departamento de Medicina e Instituto de Biología Molecular y Celular del Cáncer, Universidad de \\ Salamanca, Salamanca, Spain \\ e Fundación Pública Galega de Medicina Xenómica-Servicio Gallego de Salud, Grupo de Medicina Xenómica-Universidad de \\ Santiago de Compostela, Centro de Investigación en Red de Enfermedades Raras, Instituto de Investigación Sanitaria, Santiago de \\ Compostela, Spain \\ f Departamento de Psiquiatría, Hospital Infantil Niño Jesús, Madrid, Spain \\ s Departamento de Dermatología, Hospital Universitario de Salamanca, Salamanca, Spain \\ h División de Biomedicina Epitelial, Centro de Investigaciones Energéticas, Medioambientales y Tecnológicas, Centro de \\ Investigación en Red de Enfermedades Raras (CIBERER), Departamento de Bioingeniería, UC3M, Madrid, Spain \\ ' Miembro de la Asociación Española de Ictiosis (ASIC), Madrid, Spain \\ j Departamento de Dermatología, Facultad de Medicina, Universidad de Muenster, Muenster, Germany
}

\section{KEYWORDS \\ Ichthyosis; \\ Keratinization \\ disorders; \\ Ichthyosiform \\ congenital \\ erythroderma}

\begin{abstract}
On June 22, 2012 the First Symposium of Ichthyosis Experts in Spain was held at the Hospital Ni $\sim$ no de Jesús in Madrid. It was a one-day symposium for dermatologists, pediatricians, and physicians-in-training interested in this disease, as well as for other health care profes-sionals involved in the care of patients with ichthyosis. The aim of the meeting was to try to structure the care of ichthyosis patients in Spain. As happens in other rare diseases, because of the low prevalence of ichthyosis and the absence of designated referral centers, the number of patients treated in each center is very low and few dermatologists have any real clinical experience with this condition or know how to order diagnostic genetic tests. This article sum-marizes the presentations given at the symposium and is intended as a reference for anyone interested in the subject.
\end{abstract}

\footnotetext{
* Corresponding author.

E-mail address: ahernandez_hnj@yahoo.es (A. Hernández-Martín).
} 


\section{PALABRAS CLAVE}

Ictiosis;

Trastornos de la queratinización; Eritrodermia ictiosiforme congénita

\section{Jornada de expertos en ictiosis}

Resumen El día 22 de junio de 2012 se celebró en el Hospital Ni ₹no Jesús la I Jornada de expertos en ictiosis, una jornada monográfica dirigida a dermatólogos, pediatras y médicos en formación interesados en esta enfermedad, así como al resto de profesionales sanitarios que participan en su atención. El objetivo de la l Jornada de expertos en ictiosis fue intentar estructurar la atención de los pacientes con ictiosis en España. Como ocurre con el resto de las enfermedades raras, su escasa prevalencia y la ausencia de centros de referencia formales diluyen el número de pacientes atendidos en cada centro, y pocos dermatólogos tienen verdadera experiencia clínica o conocen la manera de solicitar diagnóstico genético. En este artículo se resumen las ponencias expuestas en la Jornada para consulta de aquellas personas interesadas en el tema.
Ichthyosis is the collective name for a group of inherited disorders of keratinization characterized by the presence of hyperkeratosis and/or scaling. Despite the similarity of the clinical presentation of some of these disorders, each one is the result of a specific genetic abnormality and the inheritance pattern is Mendelian. As there is no definitive cure for these disorders and management of the symptoms can be very difficult, ichthyoses have a significant impact on patients' lives and the dynamics of their families.

The First Symposium of Ichthyosis Experts in Spain was held on June 22, 2012 in the Hospital Niño Jesús in Madrid. This was a one-day symposium for dermatologists, pediatricians, and physicians-in-training interested in this disease, as well as for other health care professionals involved in the care of patients with ichthyosis. The symposium program included presentations by experts in the diagnosis, treatment, and care of patients with ichthyosis and by members of the board of the Spanish Ichthyosis Association (ASIC). The event was supported by the European Together Against Genodermatosis (TAG) network and received financial and organizational support from Pierre Fabre Laboratories International and its Spanish subsidiary.

The aim of the First Symposium of Ichthyosis Experts was to try to structure the care of ichthyosis patients in Spain. As happens in other rare diseases, because of the low prevalence of ichthyosis and the absence of designated referral centers, the number of patients treated in each center is very low and few dermatologists have any real clinical experience with this condition or are familiar with the procedure for ordering diagnostic genetic tests. This article summarizes the presentations made at the conference for the information of those interested in the subject.

\section{Summary of Presentations}

The opening remarks were made by Dr. Antonio Torrelo, head of the dermatology department in the Hospital Niño Jesús, and Dr. Ángela Hernández, staff dermatologist in the same hospital and symposium coordinator. The day's program was divided into 4 parts: the first part mainly clinical (Dr. Hernández, Dr. de Lucas, Dr. Torrelo and Dr. Casco); a second part focusing on molecular science (Professor González Sarmiento, Dr. Vega and Dr. Larcher); a third part dealing with the social repercussions of the disease (Professor Unamuno and members of $\mathrm{ASIC}$ ); and a fourth part about difficult-to-diagnose cases.

\section{Pathophysiology of Keratinization Disorders}

\section{Dr. Ángela Hernández. Staff Dermatologist at the Hospital Infantil Niño Jesús, Madrid}

The most generally accepted biological model describes the epidermis as a wall in which the bricks are keratinocytes and the cement that binds them together is the intercellular substance. Keratinization is a process involving a series of structural and metabolic changes in keratinocytes that starts at the basal layer of the epidermis (the innermost layer of basal keratinocytes) and continues up to the stratum corneum (the outermost epidermal layer, composed of corneocytes). Corneocytes are cells without nuclei and organelles; they are enclosed in an external envelope (the cornified envelope) and contain keratin filaments encased in a protein matrix. The keratin filaments are specific to the tissue and the degree of cell differentiation, varying according to the epidermal stratum where they are located and the tissue type (specific keratins exist for nails, hair, mucous membranes, and skin). The protein matrix is essentially composed of filaggrin, a histidine-rich protein whose precursor is profilaggrin. In addition to these structural proteins there are others having enzymatic activity, such as epidermal transglutaminase, an enzyme that promotes the creation of the cornified envelope by establishing covalent bonds between the structural proteins. The intercellular substance, mainly lipid, controls intercellular permeability and modulates flaking by way of lipases, proteases, and protease inhibitors. Our evolving understanding of the pathophysiology of ichthyosis is making it possible for us to explain the effect of each biomolecular abnormality on keratinization and the associated clinical manifestations in each case.

\section{Extracutaneous Manifestations of Ichthyosis}

\section{Dr. Antonio Torrelo. Head of the Dermatology Department of the Hospital Infantil Niño Jesús, Madrid}

The extracutaneous manifestations of ichthyosis can be caused by the skin disorder itself or by a homeostatic imbalance secondary to impaired epidermal barrier function. They can also be the result of genetic abnormalities 
that affect other organs, as is the case of the syndromic ichthyoses. Ichthyosis can affect any cutaneous tissue, including the mucous membranes and skin adnexa. Thus, it is not uncommon for patients to present ectropion or eclabium caused by periorificial retraction, keratitis secondary to the ectropion or to friction with scales, hearing loss due to extensive scaling in the external auditory canal, dysphonia due to keratinization of the vocal cords, hypotrichosis, nail dystrophy, or hypohidrosis. In neonates, epidermal barrier function impairment is not only severe in certain rare forms of ichthyosis, such as Netherton syndrome and harlequin ichthyosis, but also in collodion babies. The syndromic ichthyoses can be associated with severe abnormalities derived from the underlying genetic disorder. Some of these, such as Refsum syndrome and neutral lipid storage disease, can be fatal. Others are associated with significant morbidity caused by neurological involvement (Sjögren-Larsson syndrome, MEDNIK [mental retardation, enteropathy, deafness, neuropathy, ichthyosis, keratodermia] syndrome, CEDNIK [cerebral dysgenesis, neuropathy, ichthyosis, and palmoplantar keratoderma] syndrome), musculoskeletal disorders (chondrodysplasia punctata), sensorineural deafness and blindness (KID, that is, keratitis, ichthyosis and deafness, syndrome), or mental retardation (trichothiodystrophy). The care of patients with ichthyosis requires a multidisciplinary approach and their treatment must be properly managed by the dermatologist.

\section{New Clinical Classification of the Ichthyoses}

\section{Dr. Raúl de Lucas. Head of Pediatric Dermatology at the Hospital Universitario La Paz, Madrid}

In October 2010, the Journal of the American Academy of Dermatology published a new consensus statement on the classification of ichthyoses, which has proved to be a tool of extraordinary clinical utility. ${ }^{1}$ In total, 36 different types of ichthyosis, some very rare, are currently included in the classification. This new classification achieved international consensus on ichthyosis nomenclature and led to the elimination of terms such as bullous congenital ichthyosiform erythroderma and epidermolytic hyperkeratosis, both of which referred to the same disease. The ichthyoses are divided into subgroups according to their frequency, the Mendelian inheritance pattern, and according to whether they are associated with extracutaneous signs or not (syndromic and non-syndromic ichthyosis respectively). Ichthyosis vulgaris and nonsyndromic X-linked ichthyosis are the only common forms of the disease. The group of nonsyndromic ichthyoses includes the autosomal recessive congenital ichthyoses $(\mathrm{ARCl})$ and the keratinopathic ichthyoses. The umbrella term $\mathrm{ARCI}$ refers to lamellar ichthyosis, harlequin ichthyosis, nonbullous congenital ichthyosiform erythroderma (and its intermediate spectrum), generalized and acral selfhealing collodion baby, and bathing suit ichthyosis. The term keratinopathic ichthyosis covers the disorders previously denominated bullous congenital erythrodermas or epidermolytic hyperkeratosis, which are now called epidermolytic ichthyosis. The syndromic ichthyoses are classified into 4 subgroups according to mode of inheritance, the organ usually affected (hair, nervous system), fatal disease course, and other signs (a miscellaneous group). This classification may change in the future when as yet unknown biomolecular aspects are elucidated, but today consultation of this recent classification is essential for an understanding of the disease and the correct diagnosis of these patients because it enumerates the clinical, histologic, and molecular features of each type of ichthyosis.

\section{Use of Histologic Diagnosis in Ichthyosis}

\section{Dr. Fernando Casco. Pathologist at the Hospital Infantil Universitario Niño Jesús, Madrid}

The histologic study of ichthyoses requires careful correlation of the clinical and histopathological findings because tissue findings alone are not specific. In most cases, histology will reveal hyperkeratosis, irregular acanthosis, and variable vasodilatation, findings consistent with a diagnosis of $\mathrm{ARCl}$ (formerly nonbullous congenital ichthyosiform erythroderma), the most common clinical form. Despite this relative lack of specificity, histology can sometimes provide information that can support or rule out a diagnosis. For example, the absence of a granular layer is a finding characteristic of ichthyosis vulgaris and one that allows us, in case of doubt, to distinguish this disease from X-linked ichthyosis, a disorder in which the granular layer is normal. In other cases, the presence of microscopic blisters and acantholytic fissures may orient the diagnosis towards epidermolytic ichthyosis even when there is no clinical disruption of the epidermis. There is no doubt, however, that clinical findings (and above all the results of biomolecular studies) are essential for the accurate diagnosis of ichthyosis. Electron microscopy is another useful tool that complements conventional microscopy; however, it is not available in most Spanish hospitals, the equipment is expensive, and interpretation of the results requires expertise.

\section{Genetic Diagnosis of Ichthyosis}

\section{Professor Rogelio González Sarmiento. Unidad de Medicina Molecular, Departamento de Medicina e Instituto de Biología Molecular y Celular del Cáncer, Universidad de Salamanca}

The human genome is composed of 3 billion nucleotides, of which fewer than $10 \%$ form genes that encode proteins. While certain disorders are caused by mutations in a single gene (monogenic), mutations in different genes can also produce similar phenotypes (polygenic). In ichthyosis, an example of monogenic inheritance is epidermolytic ichthyosis, a group of conditions with a constant genotypephenotype relationship due in all cases to mutations in $\mathrm{K} 1$ or K10 keratins. By contrast, this close genotype-phenotype correlation is not present in the $\mathrm{ARCl}$ and at least 7 genes are involved in the pathogenesis of this group of disorders (TGM1, ALOXE3, ALOX12B, NIPAL4, PNPLA1, CYP4F22, and $A B C A 12)$. Today, the genetic mutations responsible for 
almost all forms of ichthyosis have been identified and, fortunately for our patients, both our own laboratory and other Spanish laboratories can provide a precise genetic diagnosis to determine the molecular abnormality responsible for the skin phenotype. In the future it will be possible to treat the molecular defect and to determine before birth whether the child of a carrier family will have the disease. However, since we are still finding cases in which the precise molecular defect has not yet been identified we must continue to study patients with these disorders to identify additional genetic abnormalities. To obtain more information about genetic testing for patients with any type of ichthyosis, contact Rogelio González Sarmiento (gonzalez@usal. es).

\section{Dr. Ana Vega. Fundación Pública Galega de Medicina Xenómica-Servicio Gallego de Salud, Grupo de Medicina Xenómica-Universidad de Santiago de Compostela, Centro de Investigación en Red de Enfermedades Raras, Instituto de Investigación Sanitaria, Santiago de Compostela}

Our work began 5 years ago with a clinical and genetic study of patients with $\mathrm{ARCl}$ in Galicia. The DNA study involved the analysis of point mutations in the TGM1, ALOXE3, ALOX12B, NIPAL4, and CYP4F22 genes. We identified mutations in 12 of the 16 families in the study: 11 in TGM1 and 1 in ALOXE3. ${ }^{2}$ Several families had the same mutation in the TGM1 gene, and some of them were homozygous. These findings led us to conduct a haplotype study, which confirmed the presence of founder mutations in our population. The Fundación Ramón Areces recently granted us funding to study the genetic and clinical characterization of Spanish patients with ARCI. One of the objectives is to identify all Spanish patients with this condition and recruit them to the study. The projects' other objectives include characterizing the clinical features of these cases, analyzing the genes identified to date and, using the latest technologies, identifying new genes that might be involved in the disease and establishing genotypephenotype correlations. This is a multicenter project open to all those who are interested in participating. Please contact us at the following email addresses: ana.vega@usc.es, mginartev@aedv.es, ladrizos@hotmail.com and Laura Fachal (laura.fachal@usc.es).

\section{The Multidisciplinary Approach in Ichthyosis: Psychological Care}

\section{Dr. José Luis Pedreira Massa. Staff Psychiatrist. Hospital Infantil Niño Jesús, Madrid}

The skin is the system of the human body most closely connected to how we relate to others because it constitutes our calling card and our visible identity. In medicine, it is the most visible system and the organ most often examined and most comprehensively described; it is also the organ we know least about. Furthermore, the presence of skin disease is closely associated with failures and inadequacies in the structuration of the self. In ichthyosis, the patient's experience with the disease will be greatly influenced by factors related to the patient and his or her family as well as by the support they receive from the health care system. However, in general, the greater the visibility and awareness of a chronic disease, the greater will be the effort made by the patients, families, and society to adapt. Patients and their families will also be more likely to receive the social and health care support they need. As is the case with other genetic diseases, in ichthyosis the information provided by medical professionals is crucial in helping family and friends to adapt to the situation. It may be the first information received by the family (many of whom may not have any prior knowledge or a family history of the disease). It can serve to counteract the pressure within the family and the family circle to find a guilty party and it can help to reduce their disorientation when they interact with health care professionals. How well those affected will cope with their first encounter with the disease will be determined by the language used to ensure that they understand the situation and its implications, the impact of the revelation, and the proposal of realistic solutions and possible future preventive measures. They will also need continued support to help them adapt to the new circumstances; this should be appropriate to the different phases of the disease and be aimed not only at caring for the patient's mental health but also for that of the parents, healthy siblings, and caregivers.

\section{Collodion Baby and Congenital Erythroderma: Clinical Management and Course}

\section{Professor Heiko Traupe. Professor of Dermatology. University of Muenster, Germany}

During the first weeks or months after birth, the life of an infant with ichthyosis may be threatened by severe impairment of the epidermal barrier. Harlequin ichthyosis poses the most serious threat during this period and in such cases the outcome is often fatal. The collodion baby is a presentation common to various types of ichthyosis: at birth the neonate is encased in a shiny transparent sheath, which sometimes limits joint mobility. The most common systemic problems affecting the collodion baby include intense transepidermal water loss (TEWL) and varying degrees of hypothermia and hypernatremic dehydration. These infants must be placed in an incubator and they require a humid environment, at least initially. Emollients with a high lipid content are applied to maintain skin moisture. Eclabium and ectropion can be severe and require particular attention. In most cases, the course is favorable, but fatal complications occur in up to $10 \%$ of these patients. In other cases the children are born with severe erythroderma in which the inflammatory component is greater than the desquamative one; these forms include Netherton syndrome, peeling skin syndrome, and chondrodysplasia punctata. In addition to requiring measures aimed at maintaining the hydroelectrolyte balance, erythrodermic patients also benefit from the application of creams containing glycerol and dexpanthenol and oil-based products in general. The long-term course depends on the genetic mutation responsible for each type of ichthyosis. 


\section{Treatment of Ichthyosis}

Professor Heiko Traupe. Professor of Dermatology. University of Muenster, Germany

The development of hyperkeratosis in ichthyosis not only depends on the genetic disorder responsible for the condition in each case, but also on the body's homeostatic response, which triggers epidermal hyperproliferation to compensate for TEWL. To date the only treatment options we have are oral and topical therapies that alleviate hyperkeratosis or facilitate the temporary removal of excess skin. The most widely used products include emollients-such as $\alpha$-hydroxy acid creams, urea, lactic acid, glycerol, and dexpanthenol-some of which also have a keratolytic effect. The application of salicylic acid and white petrolatum ointment is not recommended because of the danger of metabolic acidosis when this product is applied on large areas or in newborn infants. Patients with lamellar ichthyosis require a long daily bath, mechanical removal of scales (including those in the external auditory canal), and the application of topical products at least twice a day. Bicarbonate added to the bath water appears to promote exfoliation, probably because it destabilized the intercellular junctions. The daily application of topical products is time consuming and the products used often stain clothing; these inconveniences lead many patients to abandon treatment. Oral retinoids are effective, but their long-term safety profile is not as good as that of topical treatments. Today, new treatments with topical tazarotene and oral liarozol are being tested and there are great hopes for the possibility of developing an enzyme replacement therapy based on the topical application of transglutaminase.

\section{Lessons Learned from Experience}

\section{Pablo de Unamuno. Former Head of Department of the Hospital Universitario de Salamanca}

The ichthyoses are a very clinically heterogeneous group of disorders, but it has only been in recent decades that the underlying molecular causes have been elucidated. Salamanca was the cradle of the clinical study of ichthyosis in Spain, and for decades researchers there have investigated the occurrence of the disease within family groups, and have even identified individuals who were unaware that they were genetically related. Over 40 years ago, baptismal records in the churches of the region's towns and villages were analyzed to create detailed genetic trees that provided information on the inheritance pattern of the disease. Subsequent collaboration with the genetics laboratory led by Professor Rogelio González Sarmiento in the Department of Biomedicine at the University of Salamanca made it possible to complete the study of many cases of patients with $\mathrm{X}$-linked ichthyosis and lamellar ichthyosis that had been perfectly catalogued from the clinical standpoint. However, independently of the novel and now almost indispensable biomolecular diagnosis, daily care of these patients was always the primary concern. Before oral retinoids became available and at a time when topical care was difficult to perform for cultural and hygiene reasons, the clinical management of these patients was a major social problem. When they underwent psychological assessment, these children identified themselves in drawings as individuals with black patches on their skin, and pointed unfalteringly to their mothers when they were asked who was to blame for their problem. They were not, therefore, oblivious to the problems affecting their physical appearance, nor were they unaware of the role played by genetics when they pointed to their mothers as the person responsible. Despite advances in research and generalized access to oral therapy, patients with ichthyosis still need our support and understanding.

\section{Looking Towards the Future: Humanized Models of Ichthyosis and other Hyperkeratotic Disorders}

Dr. Fernando Larcher and Marcela del Río. División de Biomedicina Epitelial, Centro de Investigaciones Energéticas, Medioambientales y Tecnológicas, Centro de Investigación en Red de Enfermedades Raras, Departamento de Bioingeniería, UC3 M, Madrid

There are currently no cures for most of the hereditary skin diseases (genodermatosis). However, a great deal of work is being done to develop effective treatments, including cell and gene therapies. To evaluate the efficacy and safety of these new approaches in the preclinical phase we need clinically relevant models. Although transgenic mouse models (including knock-out models) are very valuable tools for understanding the molecular mechanisms of disease, they are not generally a reliable substitute for the human condition, particularly in the case of skin disorders. In fact, the significant histologic differences between mouse and human skin make murine models of skin disease relatively useless for research into therapeutic responses. The use of humanized models is a much more reliable system. Through the use of the best cutaneous bioengineering methods and starting with skin biopsies obtained from patients, our group has been able to model several genetic skin diseases. Initially, we created models of different kinds of bullous epidermolysis and other genodermatoses, and more recently we have focused on disorders of epidermal differentiation. Using a deconstruction-reconstruction approach, we have created models for congenital pachyonychia, ${ }^{3}$ Netherton syndrome, ${ }^{4}$ and lamellar ichthyosis. ${ }^{5}$

\section{What Patients Need}

\section{The Leadership Team of the Spanish Ichthyosis Association}

Our names are Inma and Chema and we are the parents of Samuel and Genoveva. We first met, albeit at a distance, 5 years ago through our children when we joined the ASIC. Since then we have shared a common commitment and a common destiny-to work every day with enthusiasm and a sense of purpose to make the lives of our children and 
our own lives as parents as normal as possible. As you all know, the birth of a child is the most beautiful moment in a parent's life, but it was not in our case. Assailed by an endless series of doubts and uncertainties, we had to learn how to care for our children in many ways that are not written in any book and without anyone to teach us. Our children's skin requires special care, and this means that we spend 2 to 3 hours every day dealing with ichthyosis: 2 baths a day lasting at least 30 minutes each, 5 or 6 applications every day of emollient and keratolytic creams, regular mechanical exfoliation with a pumice or tweezers, artificial tears several times a day to lubricate the eyes, and regular follow up visits with numerous specialists. Remember that the daily physical and psychological toll of ichthyosis affects everyone in the family. Sadly, ichthyosis is our calling card, and the reaction of other people is always more hurtful than the wounds caused by the disease. Can you imagine the depths of our suffering? We live in the hope that all of you who can work with us will do so. We ask you to help through research or the coordination of care: we need centers of reference staffed with doctors who are experts in our disease (www.ictiosis.org).

\section{Conclusions}

\section{Dr. Angela Hernández. Staff Dermatologist at the Hospital Infantil Niño Jesús, Madrid}

Dermatologists working primarily with children are familiar with the problems faced by patients who have genetic skin diseases. A diagnosis of ichthyosis heralds grave difficulties in the daily life of patients and their families, due in part to the disease itself but also to the lack of knowledge and understanding of the condition within the health care system. A recent study estimated the prevalence of $A R C l$ in Spain to be between 7.2 and 16.2 cases per million population, an estimate that would suggest that there are at least 288 individuals affected by this type of ichthyosis in the country. ${ }^{6}$ One of the most important conclusions of that study was that most of these patients are not treated in a specialized setting; that is, they do not generally have access to a hospital staffed by expert professionals and equipped with the necessary material resources. The evidence plainly shows that the care of these patients could be improved. As there are no officially recognized centers of reference in Spain for these rare diseases, it is impossible to refer affected patients to a hospital that can offer them the best medical attention for their condition. Despite the decentralized structure of the Spanish health care system, in the case of these rare disease, the authorities should set aside political interests and understand the need to work together for the benefit of the patient. We should never lose sight of the ultimate goal of centers of reference: to provide affected patients with the best care from birth. The aim is not to label the disease but rather to inform parents about their child's prognosis, to anticipate and treat complications, and eventually to facilitate access to genetic counseling and to support these patients and their families throughout their lives. To achieve these objectives, centers of reference for ichthyosis are urgently needed in Spain

\section{Ethical Disclosures}

Protection of human and animal subjects. The authors state that no experiments were performed on humans or animals for this investigation.

Confidentiality of data. The authors declare that no private patient data are disclosed in this article.

Right to privacy and informed consent. The authors declare that no private patient data are disclosed in this article.

\section{Conflicts of Interest}

The authors declare that they have no conflicts of interest.

\section{References}

1. Oji V, Tadini G, Akiyama M, Blanchet Bardon C, Bodemer C, Bourrat $E$, et al. Revised nomenclature and classification of inherited ichthyoses: results of the First Ichthyosis Consensus Conference in Sorèze 2009. J Am Acad Dermatol. 2010;63:607-41.

2. Rodríguez-Pazos L, Ginarte M, Fachal L, Toribio J, Carracedo A, Vega A. Analysis of TGM1, ALOX12B, ALOXE3, NIPAL4 and CYP4F22 in autosomal recessive congenital ichthyosis from Galicia (NW Spain): evidence of founder effects. $\mathrm{Br} J$ Dermatol. 2011;165:906-11.

3. García M, Larcher F, Hickerson RP, Baselga E, Leachman SA, Kaspar RL, del Rio M. Development of skin-humanized mouse models of pachyonychia congenita. J Invest Dermatol. 2011;131:1053-60.

4. Di WL, Larcher F, Semenova E, Talbot GE, Harper JI, del Rio M, et al. Ex-vivo gene therapy restores LEKTI activity and corrects the architecture of Netherton syndrome-derived skin grafts. Mol Ther. 2011;19:408-16.

5. Aufenvenne K, Rice RH, Hausser I, Oji V, Hennies HC, Rio $M D$, et al. Long-term faithful recapitulation of transglutaminase 1-deficient lamellar ichthyosis in a skin-humanized mouse model, and insights from proteomic studies. J Invest Dermatol. 2012;132:1918-21

6. Hernandez-Martin A, Garcia-Doval I, Aranegui B, de Unamuno P, Rodriguez-Pazos L, Gonzalez-Ensenat MA, et al. Prevalence of autosomal recessive congenital ichthyosis: a population-based study using the capture-recapture method in Spain. J Am Acad Dermatol. 2012;67:240-4. 